\title{
A Glance Backwards is Growth: By Recognizing where Metropolitan Daily Newspapers Came From over the last 30 Years - A Strategic Business Model for the Future Can Be Proposed
}

\author{
By Adam Pitluk*
}

\begin{abstract}
Since the Internet became less of a novelty and more of a cultural paradigm, global society has turned to the web for up-to-the-minute updates of news and events. One casualty of this new 24hour news cycle was the American newspaper. No longer the medium by which a digital society receives its news, the American newspaper has slowly limped off to its dying place, as day-old news does not attract readers with the same frequency that it did before the rise of the Internet. Dying mediums do not attract advertisers. A decline in advertising means a decrease in operating budgets, and that means fewer reporters and editors. Part of the reason newspapers were not ready for the technology boom is because management lacked the business acumen and marketing prowess to ready itself for a changing landscape. Newsroom managers were tone deaf to the calls of their readers to innovate. Newspaper response to the Internet was to put all their content online for free, assuming that once accustomed to receiving their news online, readers would come around and agree to pay for online subscriptions. Tellingly, the hierarchical newsroom management model remained unchanged, and news consumers' habits changed around them, thereby rendering print newspapers obsolete. This paper explores the historic downfall of the print newspaper and proposes a new newsroom model that can save the American newspaper.
\end{abstract}

Keywords: digital media, hierarchical management, newspapers, media management.

\section{Introduction}

American journalism, and to a large extent the American metropolitan daily newspaper, has long been in the conversational crosshairs of readers and newsroom executives on the topic of objectivity (Schudson, 1981). In the 20th century, newspapers received the ire of the power elite when in 1952, democrats complained about one-party press bias against Aldai Stevenson (Schudson, 1981). Of course, the idea of newspaper bias and the editorial boards failing to be objective long predates the 1950s, but when broadcast newscasts began to become more mainstream throughout the ' $50 \mathrm{~s}$ and more so into the ' $60 \mathrm{~s}$, newspapers began to feel pressure to espouse openly their objectivity (Picard, 2011).

The press bias rhetoric crossed the political aisle in the late 1960s and early '70s when the Richard Nixon/Spiro Agnew administration accused newspapers and broadcast television newscasts of being too liberal (Schudson, 1981). While the public was watching, newspapers were forced to cope with the advent of broadcast newscasts, and while newspapers continued to make record profits and returns as the decades ticked by, news managers became tone deaf to the

*PhD Student, University of Oklahoma, USA. 
wants and needs of the readers and they continued to set the agenda from their hierarchical organizational perches (Gade, 2004).

Part of the reason that newspapers have historically been viewed as not being objective is that their reporters would go talk to one person on the left, then another on the right, and then hold up the proverbial newspaper and proclaim that they have done their job and that they are objective (Gade, 2004). And why, historically, were newspapers and their managers not held accountable for their responsibility to demonstrate and explain the concept of objectivity to their readers? The 30,000-foot answer is because sociologists have shown very little interest in the study of newspapers' effect on the general public (Carey, 1982). According to Carey (1982), although there are examples of fine work that sociologists have done to illustrate an interest in and understanding of the news press and the mass media, "sociology has not accorded the social intuitions of the mass media the same systematic and persistent attention lavished on small groups, formal organizations, or demographic change" (p. 1182).

Some key concepts and theories point to additional research that needs to be done in order to understand where newspapers are coming from, and where they are headed in the future. Lacy, Stamm, and Martin (2014) shed light on a habitual newsroom situation - one that has been happening right under reporters' noses for 30 years. It is this situation that helped put newspapers in the current economic plight they are in (Lacy et al., 2014). And the situation is this: newsroom managers did not - for more than three decades - have a strategic plan for the future (Lacy et al., 2014).

The industry has little to no long-term strategy, so it essentially bounces from one environmental change in the industry to the next (Massey, 2016). This is a reactionary response, which is shortsighted, isolated, and from a financial perspective, unsustainable (Bagdikian, 1972). To wit, news media firms have a strategy to consolidate through acquisitions and mergers, and by doing so increase their market dominance (oligopoly or near monopoly) and economies of scale (Lacy et al., 2014). This strategy is a mass media strategy, where the number of media firms was relatively small, market share was high, entry barriers (start-up costs) into media were high, and competition was comparatively much less.

Another concept of concern to 20th and 21st century newsrooms involves knowledge gaps (Donohue, Tichenor, \& Olien, 1975). Top newsroom management lack the knowledge required to craft intelligent and strategic responses to environmental fluctuation, and they also lack the organizational influence to do so (Lacy et al., 2014). In the dynamic exchange between news, business and technology people, the journalists always lose out because they do not have the knowledge base to consider non-hierarchical, forward-thinking decisions (Weng, 2000). This is not because journalism has no economic value; it does. Rather, this is because the people managing the newsroom do not know how to craft and lead change initiatives (Chan-Olmstead, 2006). Thus, the accountants have the last word (Gade \& Lowery, 2011).

The short-run orientation of newspaper managers from 1985 to 2005 contributed significantly to the current dour state of newspapers (Lacy et al., 2014). They cite the financials to support the claim that newspaper managers, in an 
attempt to account for falling circulation beginning with the advent of cable news, never addressed the crux of the problem nor considered its long-term implications (Lacy et al., 2014). Rather, what managers and publishers collectively did was to raise advertising rates, scale back newsroom personnel and scale back the reach of the news coverage and circulation, thereby forfeiting the far suburbs (Lacy et al., 2014).

Another concept is that newsrooms abandoned their traditional ad structure (Gade \& Lowrey, 2011). In so doing, publishers tried to triage the ever-opening wound by running some advertising gimmick plays like raising rates throughout the 1990s because newspapers in the 1990s (before the internet) still faced little or no local advertising competition (Lacy et al., 2014). That is when in the early 2000s, the internet caught on and bit this advertising strategy on the behind (Singer, 2003). As a result, newspapers started giving their product away online and completely devalued their content (Gade, 2004). There were also moves on the part of the larger dailies for acquisition and borrowing, but more often than not, the acquiring company assumed too much debt, a disgruntled workforce, and no clear-cut way to increase circulation in the wake of internet connectedness (Lacy et al., 2014). To wit, the internet became increasingly accessible to news consumers, first in the form of laptops, then tablets, now phones (Lacy et al., 2014). And still, newspapers, seeing the writing on the wall, failed to leverage the technology on their behalf and the results were reflected on the continuously eroding bottom line (Greer \& Mensing, 2006).

Once realizing the flawed logic of an outdated newsroom model, similar to the flawed logic of the outdated spoke-and-hub airline model (as commercial aviation failed to innovate, thereby giving rise to discount carriers), a new newspaper business model of news directly to the consumer through email not only lowers costs, but it creates a revenue stream that does not have to be passed among newsroom personnel (Brueckner, 2001; Massey, 2016). The economic wave of the future means fewer journalists, more editors who are so well steeped in the craft that they can essentially teach community journalists the tradecraft (thereby cutting operating costs), and an internet hosted product that cuts production costs (Hatcher \& Haavik, 2014).

The purpose of this paper is to illustrate that the traditional newspaper business is down, resources are down, yet digital business is growing (Barthel, 2015). While these ideas do not point so much to a failed industry as much as a failed business model for the traditional newspaper's online news component, when the economic problem is conceptualized within the concepts of the newsroom's archaic hierarchical structure, management knowledge gaps, and a diminished advertising structure, then a new, innovate business model begins to take shape (Donohue et al., 1975; Gade, 2004; Lacy et al., 2014; Hatcher \& Haavik, 2014). 


\section{Newsroom's Archaic Hierarchical Structure}

Beginning with the organizational structure of a newsroom, it is important to consider Lewin's Field Theory, Group Dynamics Theory and Action Research Theory (Burnes, 2004). The Field Theory states that one should view the status quo as being maintained by certain conditions (Burnes, 2004). As such, group behavior is an intricate set of symbolic interactions that not only have an effect on group structure, but also on the individuals who make up that group (Burnes, 2004). Kurt Lewin expanded upon the idea of group behavior when he explained Group Dynamics, or the importance of the group in influencing the behavior of its members (Burnes, 2004). It was this work that led Lewin to conceive of Action Research, which considers the group's present situation, the dangers, and most importantly, how they should be addressed (Burnes, 2004).

Lewin took these three elements and formed an integrated approach to analyzing, understanding and bringing about change at the group, organizational, and societal levels, which he called the 3-Step Model (Burnes, 2004). By unfreezing, or destabilizing the present, organizational equilibrium is thereby diluted in the run-up to discarding old behavior and successfully adopting new behavior (Burnes, 2004). Next, in the moving step, Lewin argues that one has to take into account the iterative process of accounting for all the forces at work (Burnes, 2004). Finally, in the refreezing process, managers must stabilize the group in order to ensure that new behaviors are steadied and safe from regression (Burnes, 2004). To wit, organizations must be prepared for constant change (Kanter, 1983; Drucker, 2008). Incorporating corporate processes for developing a sustainability report help identify the hurdles faced by organizations and the way in which organizational change toward improved accountability occurs (Adams \& McNicholas, 2007). This can lead to changes in sustainability performance (Adams \& McNicholas, 2007). Tellingly, Lewin's felt-need concept arises from a recognition that successful action is based on an accurate field analysis of a situation, properly identifying all possible solutions, and choosing the one that is most in line with the needs of the group (Burnes, 2004). Distilled further, the feltneed concept occurs when a person realizes that change is necessary (Burnes, 2004).

Lewin (1946) asserted that social groups and not individuals were essential to reducing inherent conflict among groups. When the groups communicated and became accustomed to each other, an inherent empathy was gained and the result was reduced (Lewin, 1946). That reduced conflict became the bedrock foundation that made change possible (Lewin, 1946).

In the context of the hierarchical management structure (top-down leadership), whether management wants to openly recognize this paradigm or not, there are two distinct social groups within an organization: management and nonmanagement (Gade \& Lowrey, 2011). Each group has different parts to plan in that organization's success (Kanter, 1983). However, one of these groups has more organizational power than the other (Kanter, 1983). Therefore, for organizational development including learning, sustainability, and for successful change to 
occur, there has to be a felt-need consensus among groups (Adams \& McNicholas, 2007; Burnes, 2004; Gade \& Lowrey, 2011).

Lewin (1946) and Kanter (1983) set the tone over the years for a belief held by many management scholars, and that belief is this: Consensus is not created by top-down initiatives. Innovation occurs when organizations leverage the diversity of their knowledge (Burnes, 2004; Kanter, 1983; Lewin, 1946). The most successful managers make an organizational structure that ensures an exchange of knowledge occurs (Adams \& McNicholas, 2007). Organizations need management, to be sure, but management must recognize that they are not the collective brainpower of the entire organization (Rasmussen, 1985). Management must design an explicit description of the functional properties of the organization in terms of an abstraction hierarchy, one that is fluid and not altogether parochial (Rasmussen, 1985).

So how does this apply to newsrooms and the organizational change that must occur in order for them to innovate and propagate? Joseph Schumpeter, the godfather of innovation research, said that the process of creativity and innovation leading to the elimination of the established order is known as creative destruction (Storsul \& Krumscik, 2013). Regarding journalism, journalists are somewhat hesitant about felt need, and have been reluctant to acknowledge the impact of the digital age and its associated loss of journalism institutional control (Singer, 2011). By and large, they do not have a felt need to change because they have become accustomed to being the agenda setters (Burnes, 2004; Singer, 2011). And to the extent that they recognize a need to change, journalists are leery about learning a new trick, as it were, because to do so would be to challenge the longstanding hierarchical order (Singer, 2011); to do so would be to challenge the hard work they have done while toiling in the newsroom with the hopes of being promoted to editor (Gade, 2004). Essentially, the knowledge base of journalism and of newspapers in particular has changed from mass media to digital media over the last 20 years (Bennett, 2015).

As a result, management does not really know how to change because that same management was once frontline workers, promoted through the ranks because of service and journalistic aptitude, and not because of their business acumen (Mensing, 2010). They have trouble extending a vision that is coherent enough for skeptical journalists, who after 20 years of change mandates, have little faith that management knows the answers to the digital questions (Lacy \& Sohn, 2011). And why do newspaper journalists doubt that management has the right answers? Because through their communal observations in newsrooms near and far, they no longer believe that management has the knowledge (Gade, 2004).

\section{Knowledge Gap}

To understand why journalists in metropolitan daily newspapers have essentially voted no confidence in management's ability to change and innovate, we must first look to research conducted at the University of Minnesota. Donohue et al. (1975) concluded that a principal consequence of how the mass media covers 
politics, public affairs, and social issues effects the knowledge gap. The knowledge gap, the researchers contended, is due to the uneven dissemination of information in society. Knowledge is not evenly acquired by every member of society because people with a higher socioeconomic status tend to have a higher aptitude for acquiring and processing the information (Weng, 2000). Donohue et al. (1975) surveyed 15 Minnesota communities that were in various stages of conflict and concluded that the relationship between the level of conflict about local issues was the knowledge gap.

Essentially, as conflict about local issues increased, the knowledge gap tended to decline (Donohue et al., 1975). Therefore, a group of better-educated people who know more about external goings-on because of media consumption know more than people with less education (Donohue et al., 1975). Lower socioeconomic status people, defined partly by educational level but who can also be defined by their income and property ownership status, have little or no knowledge about public affairs issues. They are disconnected from news events and important new discoveries, and generally are not overly concerned about their lack of knowledge (Weng, 2000).

Donohue, Tichenor, and Olien present five reasons explaining the knowledge gap: First, people with a higher socioeconomic status have a better education, better communication skills, and a higher level of reading comprehension (Donohue et al., 1975). Second, people with a higher socioeconomic status can process information easier than someone with a lower socioeconomic status, and they can recall similar information about a topic and synthesize that newfound knowledge with older stored knowledge to form a conclusion (Donohue et al., 1975). Third, people with a higher socioeconomic status more than likely have significantly more relevant social context (Donohue et al., 1975). Fourth, people with a higher socioeconomic status are better suited to pick and choose which points they believe are important, as well as which points they would like to remember (Donohue et al., 1975). Fifth, by its very construction, mass media is produced for people with a higher socioeconomic status (Donohue et al., 1975). In the case of the 21 st century newsroom, because of the deluge of information and misinformation circulated for public consumption by citizens representing themselves as journalists, and because of the advent of deliberately fake news websites, and various peoples' social networks could perpetuate this misinformation, the nature of the news itself might reduce knowledge (Borden \& Tew, 2007; Donohue et al., 1975; Gade \& Lowrey, 2011).

Reporters seek the collective knowledge of their corporation and/or organizations, and top journalism executives have direct exposure to this knowledge thirst (Chan-Olmsted, 2006). However, the scope of the complexities is often beyond their professional knowledge, and their ability to craft solutions and to innovate has been weak (Lacy \& Sohn, 2011; Picard, 2011). The public has gradually become more dependent on the mass media for their potpourri of information as alternative channels of daily communication have been marginalized (Jenssen, 2013).

General news is not equally distributed, and according to the knowledge gap hypothesis, the gap between the most and least knowledgeable is likely to 
widen due to the pattern of media consumption, the different content of newspaper and TV, and the abilities of the audience as linked to educational differences (Jenssen, 2013). The impact of newspaper consumption on the distribution of general knowledge has been studied (Jenssen, 2013). Jenssen (2013) concludes that there is a knowledge gap between newspapers and their audience. Extrapolated further, the reason there is a knowledge gap between newspapers and their audience is because there is a knowledge gap between editors/management and reporters (Gade, 2004).

\section{Advertising Structure}

Having claimed that the hierarchical structure of newsrooms is archaic, which is a key reason why they have failed to innovate, and because of the knowledge gap that exists between management and reporters as well as between newspapers and their audience, the next pressing issue is one of economics.

During the past decade, the newspaper industry experienced significant erosion of revenue, predominantly in print advertising (Sridhar \& Sriram, 2015). The associated increase in the less-rewarding online advertising has been unable to make up for this loss, but that is hardly consoling for newspaper advertising executives or salespeople (Sridhar \& Sriram, 2015). "As a result, for every \$1 increase in online advertising between 2005 and 2011, newspapers lost \$22 in print advertising" (Sridhar \& Sriram, 2015, p. 285). While it is conceivable that the overall change in the advertising landscape contributed to the decline in print advertising, it is not clear whether the growth in online newspaper advertising aggravated or alleviated this global trend (Sridhar \& Sriram, 2015).

Advertisers exhibit a higher propensity to decrease print spending when they increase their online spending compared to the scenario when online spending either remains unchanged or even decreases (Sridhar \& Sriram, 2015). The growth in online newspaper advertising exacerbated the overall decline in print advertising (Sridhar \& Sriram, 2015). Overall, Sridhar and Sriram (2015) say 7 to 17 percent of the decline in print newspaper advertising revenues between 2005 and 2011 can be traced to the growth of online newspaper advertising. They concluded that cannibalization should be a credible consideration in the marketing decisions of newspapers (Sridhar \& Sriram, 2015).

However, since a large portion of print advertising revenue also declined for advertisers who never purchased online advertising from the newspaper, cannibalization within the newspaper is not solely responsible for the downward trajectory of print advertising (Pattabhiramaiah, 2014). Newspapers, especially major metropolitan dailies like the Dallas Morning News, abandoned local advertisers in the 1990s and elected to focus on maximizing revenue from national accounts (Borden \& Tew, 2007; Pattabhiramaiah, 2014).

As a result, when newspapers raised advertising rates (and in the process, gave incentives and made deals for national brands to advertise in multiple products and across traditional and digital platforms) they made local advertisers feel unimportant (Chandra \& Kaiser, 2014). During the recession of 2008-2010, 
as newspapers tried to get these former advertisers back, they found that local businesses had taken their business elsewhere and found other ways to invest in marketing - ways that were cheaper and more effective than the printed paper (Chandra \& Kaiser, 2014).

Although Lewin conceptualized the idea of felt need in 1946, and notwithstanding the fact that Burnes revived it as a psychology tenet 58 years later, the current media landscape is more in need of adhering to this intellectual relic of the post-war past now more than ever (Burnes, 2004; Gade \& Lowrey, 2011; Lewin, 1946; Medley \& Akan, 2008).

Look no further than the newsrooms of American newspapers over the last 20 years (Gade \& Lowrey, 2011). For decades, the newsroom followed the model of hierarchical leadership, very management heavy, leading from the top down, and siloed (Gade \& Lowrey, 2011). When the Internet came along, the media did not know how to deal with it, but they knew they had to be a part of it (Gade \& Lowrey, 2011). What newspapers did - most likely to show that they were progressive and not aging hulks - was to offer all of their content online, for free (Gade \& Lowrey, 2011). In so doing, they not only devalued their content, but they rendered their entire subscription-and-advertising-based business model obsolete (Gade \& Lowrey, 2011).

Newspapers put their content on the Internet because they saw tech savvy news consumers (usually high socioeconomic status groups they were already serving) were moving there and did not want to be left behind (Gade, 2004). Newspapers also did not have a business model for this move. They thought that people who paid for printed papers would eventually pay for online papers. These newspapers, which is to say these newspaper managers, misunderstood the online culture of free (Gade, 2004).

After all, why pay for something if you grow accustomed to getting it for free? The result was that newspapers, which were used to consistent double-digit profit margins, bucking those raked in by Fortune 500 companies (which averaged 4 percent yields), now had to adapt to 7-to-10 percent profit margins (Gade \& Lowrey, 2011). Of course, a newspaper cannot stomach diminished returns any more than an individual can stomach declining returns-oninvestment, so in the spirit of the old hierarchical structure of American media management, newspapers hedged those deflated dividends by decreasing operation and production costs (Chandra \& Kaiser, 2014). Management started laying off the foot soldiers, and newspapers began running leaner operations as a way to triage the wound inflicted by the advent of the Internet and its capability to deliver more news to more people at a greater speed (Chandra \& Kaiser, 2014). What was a money-making one-way conversation machine was forced to adapt, in Lewin-esque style, to a two-way conversation model that no longer saw the newspapers as the agenda setters that they were: Now it was the news consumers that had the power (Chandra \& Kaiser, 2014; Gade \& Lowrey, 2011). 


\section{The Wave of the Future of Newspapers}

I now wish to propose a business model that would work for contemporary newspapers. In order to do this, one must look to innovative measures taken in two different industries in order to see how change can be implemented, and how change can move the industry forward. One of those industries is commercial aviation, and the other is the company that made digital the wave in the first place, AOL.

Newspapers have high operating costs (Gade, 2004). Paper is becoming more expensive because the demand is so low that mills are shutting down. A few key players control all the domestic paper, and they are gouging the newspaper purchasers (O'Sullivan, Fortunati, Taipale, \& Barnhurst, 2017).

Here is how it works: Because newspapers have seen declining readership, there was not a need for as many mills for paper, so many shut down (O'Sullivan et al., 2017). Because printing presses are dependent on paper mills for paper, and as both depend on newspapers for business, more and more presses shut down (O'Sullivan et al., 2017). The result is that fewer presses can raise their rates because there is scant competition (O'Sullivan et al., 2017).

An industry that understands what it means to be hamstrung by inter-industry dependencies is the airline industry. Traditionally, aviation has been a capitalintensive industry (Bjelicic, 2012). The major cost to an airline historically was the financing of its jet aircraft (Bjelicic, 2012).

In the primary market, orders for new aircraft are directly dependent upon sector expectations regarding future air transport demand (Bjelicic, 2012). Prior to the financial markets crisis, market participants were highly optimistic about the future of air travel and the profits the airlines would make. One of the factors for this positive outlook was the successful business model adopted by low-cost carriers - despite the fact that the preceding decade had shown that the aviation industry is not immune to major structural shocks (September 11, SARS, Bird Flu etc.) affecting transport developments (Bjelicic, 2012).

Another factor that gained importance was fuel consumption: driven by the strong boom in the world economy, crude oil prices rose continuously into the year 2008. As a result, airlines' jet fuel costs exploded overnight and stayed high for much of 2009-2012 (Bjelicic, 2012). "Hence, numerous new aircraft orders were also [canceled] by concerns about jet fuel prices remaining high or rising even further" (Bjelicic, 2012, p. 15). The discount carriers, many of whom do not have the strong unions that the legacy carriers have, recognized this expense conundrum and made some adjustments (Bjelicic, 2012). Data envelopment analysis (DEA) was used to evaluate the technical efficiencies of 14 major US passenger airlines at transforming their inputs into available seat-miles in the year 2004 (Greer, 2006). The measures used in the analysis were labor, aircraft fuel, and fleet-wide seating capacity (Greer, 2006). There was some evidence that the seven discount carriers included in the study were more technically efficient than the seven legacy carriers (Greer, 2006). Therefore, the production cost advantage that the discount carriers have had over the legacy carriers appeared to stem in part 
from superior technical efficiency and did not originate solely in paying lower prices for certain expenses, such as labor (Greer, 2006).

Embracing technology and avoiding a spoke-and-hub framework, which is expensive, is why discount carriers are surging. It is why their stocks trade higher than the world's largest airline, American Airlines (Greer, 2006). Indeed, technology was the magic bullet that saved an archaic, fledgling airline industry.

And because of innovators like Steve Case, technology can save the fledgling newspaper industry. Case is the man who founded AOL.

In a recently released book, Case said that the first wave of the Internet was laying the groundwork and coding (2016). The second wave, he said, started in 2000 and was defined by applications and software-like Google, Facebook, Twitter - built on top of the Internet (Reese, 2016). Now, he says, we are at the dawn of the third wave.

The third wave is the concept of the "Internet of Everything", something so pervasive that every aspect of our lives either currently relies or will soon rely on Internet connectedness (Case, 2016). Whereas the first two waves had to do with hardware, software, coding and platforms, Case sees this new third wave defined by partnerships - especially between business and government (2016). New partnerships, Case believes, will be able to change the way our institutions, like healthcare, education, agriculture, and in particular, media, integrate the Internet into our lives (Reese, 2016).

Let's take Case's prediction as more than straight conjecture and apply some credence to it. If we assume that Case is right and that the third wave of Internet is upon us, then take his idea of the partnership between government and the Internet, expand it to include media, and drill down.

According to a study published by the Boston Globe, of the 10 highest paying jobs for recent college graduates, four of them were social science/humanities careers involving Internet skills (web designer: $\$ 58,000 /$ year; Internet marketer: $\$ 68,000 /$ year; network systems administrator: $\$ 69,000 /$ year; software developer: $\$ 84,000 /$ year) (Altman, 2010). These are starting salaries. People who stay with these careers and work their way up the corporate food chain have mean salaries well in the six-figures (Altman, 2010).

Let's compare these jobs with journalism jobs for recent college graduates. On average, newspaper journalists can expect to make roughly $\$ 24,000$ $\$ 25,000 /$ year (Pay Scale, 2016). The average salary for a career newspaper journalist is roughly $\$ 38,300 /$ year (2016). And for the rock stars of the profession - those men and women who dedicated their lives to the advancement of good journalism and informing the public - the high end of the pay scale taps out at around \$70,000/year (2016). That means the most successful, most seasoned, and most respected journalists in newspapers - assuming that having all of these attributes translates to being the highest paid - makes roughly the same salary as a 21-year-old network systems administrator, and less than a 21-year-old software developer. Why? Because the services provided by newspaper men and women were devalued when newspaper managers, in their hierarchical structure, started putting content on the Internet for free (Gade, 2004). Added to this, news work is no longer exclusive to journalists. Newspaper employees are being supplemented 
or replaced by people with no special training or expertise, and too often, the value of the journalism product (content) is not differentiated enough from that produced by non-professionals. And the work is not as thorough or as honest. For example, fake news is news created by whomever for reasons of deceit, but it takes no special knowledge of how to do it (just mimic news formats and styles and lie).

By applying Case's third wave theory to newspapers, if newspapers implemented a more technologically centered or Internet-driven product, then readers would not only be attracted to these products, but they would sign up to receive them via email, thereby divulging personal information that can also be utilized for marketing purposes. That data can be of tremendous use to marketers and advertisers, who would pay for a list of people who voluntarily submitted their email for a news product (Burnes, 2004). The newspaper newsroom, as it currently exists, and the hierarchical structure thereof, which they cannot seem to break away from, would cease to exist. The newsroom of this digital model would be comprised of savvy editors who can edit well, train community journalists to do the job for a fraction of what a professional journalist would do it for, and then rework the amateur copy into something that is digestible and engaging to the reader.

The target market would be the underserviced communities (usually outlying suburbs) that were abandoned by the metropolitan dailies when capital and resources dried up and they were forced to direct all their expenditures inward on the urban city centers they serve. As a result, there would be an army of citizen journalists getting paid for what they would otherwise do in any given day for free (e.g., attend county commission meetings, work with the Girl Scouts). New voices would be heard and curated by editors, who would be the only salaried employees on the payroll, thereby reducing payroll expenses and other fixed costs like travel budget for reporters. This is a decidedly more progressive approach to the way newspapers run their day-to-day operation (Mensing, 2010).

Now, integrate a mobile component to the newspaper profession, and Case's third wave theory manifests itself as an inter-dependent-cum-mutually-beneficial relationship for the citizen journalist, the editor, and the profession once the citizen journalist leaves his/her comfort zone, embraces the felt-need concept, becomes a media entrepreneur, and starts to generate enterprise story leads (Frith \& Meech, 2010).

"The mobile phenomenon has literally exploded onto the journalism world" (Frith \& Meech, 2010, p. 39). In 2010, researchers found references to mobile skills in just a little more than 2 percent of newspaper job postings (Frith \& Meech, 2010). By the end of 2012, mobile was mentioned in more than 27 percent of all newspaper news job listings - and that still lags behind mobile's prominence in online job ads (Frith \& Meech, 2010).

The demand for mobile skills (i.e. being able to report stories and post online or email content in real time) is only expected to grow as most newspapers and other news outlets see mobile traffic quickly outpacing that of their websites (Frith $\&$ Meech, 2010). Some journalism programs have rapidly developed courses in mobile newsgathering or added instruction in that area within existing classes 
(Frith \& Meech, 2010, p. 39). Still others have focused on creating courses that teach journalism students how to build mobile apps or the fundamentals of responsive design (Frith \& Meech, 2010).

Tellingly, journalism schools are prepared for the referendum on printed newspapers. Now the newspapers themselves have to swallow the very bitter pill that once the Greatest Generation, and to an extent, the Baby Boomers, are either dying out or turning their backs on the print product. Having a product that is entirely online has tremendous practical application with very little overhead (Picard, 2011). The new mobile, digital newsroom - sans reporters - can, like Lewin said in 1946, "help eager people free themselves of the fog" (Lewin, 1946, p. 201). The aforementioned is a formula to lift the fog that is hanging over newspapers.

So what are the concepts of a business model? They begin with understanding supply side (costs) vs. revenues. As indicated earlier, news firms have tried to offset failing revenues by decreasing supply side costs. They have always done this (for the past century anyway). But today they have a digital revenue problem and a digital distribution (supply side) opportunity.

Email and mobile can work together to be a distribution system. It is cheap and efficient. It is also a way to expand and benefit from ad revenues. And, with incentives, subscribers could use social media to push news firm content through larger distribution systems, which would bring more eyeballs on news content and ads that pay the news industry.

To bring the conversation full circle, the evolution of - and vitality of - the newspaper profession has its roots in Lewin's concept of felt-need. After all, "nearly all editors who have involved their newsrooms in change initiatives have suggested the key to making change work is to create a new culture. ... Change initiatives have required journalists to rethink some fundamental principles of their work: their sense of news, audience, organization, and even the purpose of journalism" (Gade, 2004, pp. 10, 11).

\section{References}

Adams, C. A., \& McNicholas, P. (2007). Making a difference: Sustainability reporting, accountability and organizational change. Accounting, Auditing \& Accountability Journal, 20(3), 382-402.

Altman, E. (2010, August 13). The top 10 highest paying post-grad jobs. Boston Globe Media. Retrieved from http://www.hercampus.com/after-college/top-10-highestpaying-post-grad-jobs.

Bagdikian, B. H. (1972). The politics of American newspapers. Columbia Journalism Review, 10(6), 8-17.

Barthel, M. (2015, April 29). Newspapers: Fact sheet. Pew Research Center. Retrieved from https://pewrsr.ch/2MTQg7Y.

Bennett, W. L. (2015). Changing societies, changing media systems: Challenges for communication theory, research and education. In S. Coleman, G. Moss, K. Parry, J. Halperin, \& M. Ryan (Eds.), Can the Media Serve Democracy? (pp. 151-163). Palgrave Macmillan UK. 
Bjelicic, B. (2012). Financing airlines in the wake of the financial markets crisis. Journal of Air Transport Management, 21, 10-16.

Borden, S. L., \& Tew, C. (2007). The role of journalist and the performance of journalism: Ethical lessons from "fake" news (seriously). Journal of Mass Media Ethics, 22(4), 300-314.

Brueckner, J. K. (2001). The economics of international code sharing: An analysis of airline alliances. International Journal of Industrial Oorganization, 19(10), 14751498 .

Burnes, B. (2004) Kurt Lewin and the Planned Approach to Change: A reappraisal. Journal of Management Studies, 41(6), 977-1002.

Carey, J. W. (1982). Review: The discovery of objectivity. American Journal of Sociology, 87(5), 1182-1188.

Case, S. (2016). The Third Wave: An Entrepreneur's Vision of the Future. Simon and Schuster.

Chandra, A., \& Kaiser, U. (2014). Targeted advertising in magazine markets and the advent of the Internet. Management Science, 60(7), 1829-1843.

Chan-Olmsted, S. (2006). A primer in strategic management for media firms. In S. ChanOlmsted (Eds.), Competitive Strategy for Media Firms (pp. 13-37). Mahwah, NJ: Erlbaum.

Donohue, G. A., Tichenor, P. J., \& Olien, C. N. (1975). Mass media and the knowledge gap hypothesis reconsidered. Communication Research, 2(1), 3-23.

Drucker, P. (2008). Introduction: Management and managers defined; management as a social function and liberal art; knowledge is all. In P. Drucker (Eds.), Management (pp. 1-25, 37-44). New York: Harper Collins.

Frith, S., \& Meech, P. (2010). Becoming a journalist: Journalism education and journalism culture. Journalism, 8(2), 137-164.

Gade, P. J. (2004). Newspapers and organizational development: Management and journalist perceptions of newsroom cultural change. Journalism \& Communication Monographs, 6(1), 3-55.

Gade, P. J., \& Lowrey, W. (2011). Reshaping the journalistic culture. In W. Lowrey, \& P. J. Gade (Eds.), Changing the news: Forces shaping journalism in uncertain times (pp. 22-42). New York: Routledge.

Greer, J., \& Mensing, D. (2006). The evolution of online newspapers: A longitudinal content analysis, 1997-2003. Internet Newspapers: The Making of a Mainstream Medium, 13-32.

Greer, M. R. (2006). Are the discount airlines actually more efficient than the legacy carriers?: A data envelopment analysis. International Journal of Transport Economics/Rivista Internazionale di Economia Dei Trasporti, 33(1), 37-55.

Hatcher, J., \& Haavik, E. (2014). "We write with our hearts" how community identity shapes Norwegian community journalists' news values. Journalism Practice, 8(2), 149-163.

Jenssen, A. T. (2013). Widening or closing the knowledge gap?. Nordicom Review, 33(1), 19-36.

Kanter, R. M. (1983). Introduction. In R. M. Kanter (Eds.), The Change Masters (pp. 1736). New York, NY: Simon \& Schuster.

Kanter, R. M. (1983). The architecture of culture and strategy change. In R. M. Kanter (Eds.), The Change Masters (pp. 278-306). New York, NY: Simon \& Schuster.

Lacy, S., Stamm, M., \& Martin, H. (2014). Short-run decisions threaten papers' long-run viability. Newspaper Research Journal, 35(4), 6-20. 
Lacy, S., \& Sohn, A. (2011). Market journalism, In W. Lowrey, \& P. J. Gade (Eds.), Changing the news: Forces shaping journalism in uncertain times (pp. 159-176). New York: Routledge.

Lewin, K. (1946). Action research and minority problems. Journal of Social Issues, 2(4), 34-46.

Massey, B. L. (2016) Resource-based analysis of the survival of independent web-native news ventures. Journalism \& Mass Communication Quarterly, 93(4), 770-788.

Medley, B. C., \& Akan, O. H. (2008). Creating positive change in community organizations: A case for rediscovering Lewin. Nonprofit Management and Leadership, 18(4), 485-496.

Mensing, D. (2010). Rethinking [again] the future of journalism education. Journalism Studies, 11(4), 511-523.

O'Sullivan, J., Fortunati, L., Taipale, S., \& Barnhurst, K. (2017). Innovators and innovated: Newspapers and the postdigital future beyond the "death of print". The Information Society, 33(2), 86-95.

Pattabhiramaiah, A. B. (2014). Essays on newspaper economics (Doctoral Dissertation). Retrieved from https://bit.ly/2KeRufS.

Pay Scale (2016, October 3). Journalist Salary. Retrieved from https://bit.ly/1KnHjLp.

Picard, R. G. (2011). Certainty and uncertainty of change in journalism. In W. Lowrey, \& P. J. Gade (Eds.), Changing the news: Forces shaping journalism in uncertain times (pp. vii-ix). New York, NY: Routledge.

Rasmussen, J. (1985). The role of hierarchical knowledge representation in decisionmaking and system management. IEEE Transactions on Systems, Man, and Cybernetics, (2), 234-243.

Reese, H. (2016, April 14). Steve case: The "third wave" of the internet will transform our institutions. Tech Republic. Retrieved from https://tek.io/1V5oLJo.

Sridhar, S., \& Sriram, S. (2015). Is online newspaper advertising cannibalizing print advertising? Quantitative Marketing and Economics, 13(4), 283-318.

Schudson, M. (1981). Discovering the news: A social history of American newspapers. Basic Books.

Singer, J. B. (2003). Who are these guys? The online challenge to the notion of journalistic professionalism. Journalism, 4(2), 139-163.

Singer, J. B. (2011). Journalism and digital technologies. Changing the news: The forces shaping journalism in uncertain times, 214-229.

Storsul, T., \& Krumsvik, A. H. (2013). What is media innovation? Retrieved from https://bit.ly/2KaeOac.

Weng, S. C. (2000). Mass communication theory and practice. Taipei: San-ming. 